\title{
Fungal sensing skin
}

\author{
Andrew Adamatzky ${ }^{*}$, Antoni Gandia ${ }^{2}$ and Alessandro Chiolerio ${ }^{1,3}$
}

\section{Abstract}

Background: A fungal skin is a thin flexible sheet of a living homogeneous mycelium made by filamento, fungus. The skin could be used in future living architectures of adaptive buildings and as a sensing living kin for soft selfgrowing/adaptive robots.

Results: In experimental laboratory studies we demonstrate that the fungal skin is ca able for cognising mechanical and optical stimulation. The skin reacts differently to loading of a weight, remov a he weight, and switching illumination on and off.

Conclusion: These are the first experimental evidences that fungal materia' can se used not only as mechanical 'skeletons' in architecture and robotics but also as intelligent skins capable for ogm ón of external stimuli and sensorial fusion.

Keywords: Fungi, Biomaterials, Sensing, Sensorial fusion, Soft robotics

\section{Introduction}

Flexible electronics, especially electronic skins [1-3h is amongst the most rapidly growing and promising ields of novel and emergent hardware. The electronic ski. made of flexible materials where electronics capable tactile sensing [4-7] are embedded. The e ect $\mathrm{e}_{\text {ic skins }}$ are capable of low level perception [8 and a be developed as autonomous adaptive devices [10]. Typical designs of electronic skins inclu thin-fil $m$ transistor and pressure sensors integrated in sic substrate [11], micro-patterned polydime loxane with carbon nanotube ultra-thin films $\lceil 12,1 \%$, a Jarge-area film synthesised by sulfurisation $\mathrm{O}_{1}$ tung ten film [14], multilayered graphene [15], Bbons [3], Polyethylene terephthalate $\left(\mathrm{P}^{\top} \mathrm{T}\right)$ base ilyer electrodes [16], digitally printed hybri $\mathrm{e}_{\mathrm{A}}$ trodes hor electromyographic recording [17] of for pie asistive pressure sensing [18], or channel filled with conductive polymer [19].

Whilst exi cing designs and implementations are high impa al, the prototypes of electronic skins lack

*Corres ondence: andrew.adamatzky@uwe.ac.uk

${ }^{1}$ Unconventional Computing Laboratory, UWE, Bristol, UK

Full list of author information is available at the end of the article a ca city to self-repair and grow. Such properties are sefu and could be necessary, when an electronic skin is sed in e.g. unconventional living architecture [20], oft and self-growing robots [21-24] and development of intelligent materials from fungi [25-28]. Based on our previous experience with designing tactile, colour sensors from slime mould Physarum polycephalum [29-31] and our recent results on fungal electrical activity [32-34] we decided to propose a thin layer of homogeneous mycelium of the trimitic polypore species Ganoderma resinaceum as a live electronic skin and thus investigate its potential to sense and respond to tactile and optical stimuli. We call the fungal substrate, used in present paper, 'fungal skin' due to its overall appearance and physical feeling. In fact, several species of fungi have been proposed as literal skin substitutes and tested in wound healing [35-40].

The paper is structured as follows. We introduce the protocol for growing the fungal skin and the methods of electrical activity recording in "Methods" section. Patterns of electrical activity of the fungal skin are analysed in "Results" section. Results are considered in a wider context and directions of future studies are outlined in "Conclusion" section.

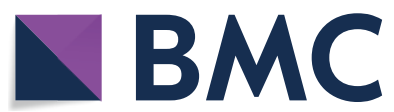

c) The Author(s) 2021. This article is licensed under a Creative Commons Attribution 4.0 International License, which permits use, sharing, adaptation, distribution and reproduction in any medium or format, as long as you give appropriate credit to the original author(s) and the source, provide a link to the Creative Commons licence, and indicate if changes were made. The images or other third party material in this article are included in the article's Creative Commons licence, unless indicated otherwise in a credit line to the material. If material is not included in the article's Creative Commons licence and your intended use is not permitted by statutory regulation or exceeds the permitted use, you will need to obtain permission directly from the copyright holder. To view a copy of this licence, visit http://creativecommons.org/licenses/by/4.0/. The Creative Commons Public Domain Dedication waiver (http://creativecommons.org/publicdomain/zero/1.0/) applies to the data made available in this article, unless otherwise stated in a credit line to the data. 


\section{Methods}

Potato dextrose agar (PDA), malt extract agar (MEA) and malt extract (ME) were purchased from SigmaAldrich (USA). The Ganoderma resinaceum culture used in this experiment was obtained from a wild basidiocarp found at the shores of Lago di Varese, Lombardy (Italy) in 2018 and maintained in alternate PDA and MEA slants at MOGU S.r.l. for the last 3 years at 4 ${ }^{\circ} \mathrm{C}$ under the collection code $019-18$.

The fungal skin was prepared as follows. G. resinaceum was grown on MEA plates and a healthy mycelium plug was inoculated into an Erlenmeyer flask containing $200 \mathrm{ml}$ of $2 \% \mathrm{ME}$ broth (MEB). The liquid culture flask was then incubated in a rotary shaker at $200 \mathrm{rpm}$ and $28{ }^{\circ} \mathrm{C}$ for 5 days. Subsequently, this liquid culture was homogenised for $1 \mathrm{~min}$ at max. speed in a sterile $1 \mathrm{~L}$ Waring laboratory blender (USA) containing $400 \mathrm{~mL}$ of fresh MEB, the resulting $600 \mathrm{~mL}$ of living slurry were then poured into a 35 by $35 \mathrm{~cm}$ static fermentation tray. The slurry was let to incubate undisturbed for 15 days to allow the fungal hyphae to inter-mesh and form a floating mat or skin of fungal mycelium. Finally, a living fungal skin c. $1.5 \mathrm{~mm}$ thick was harvested (see texture of the skin in Fig. 1a), washed in sterile demineralised water, cut to the size $23 \mathrm{~cm}$ by $11 \mathrm{~cm}$ and placed onto a polyurethane base to keep electrodes stable during the electrical characterisation steps (Fig. 1b).

The electrical activity of the skin was measured as lows. We used iridium-coated stainless ste sub-der mal needle electrodes (Spes Medica S r.I. Ita with twisted cables. The pairs of electrode were inser ed in fungal skin (Fig. 1b). In each pair $\mathrm{w}$ recorded a difference in electrical potential between elertrodes. We used ADC-24 (Pico Technol UK) high-resolution data logger with a 24-bit Anarog « Jigital converter, galvanic isolation and are-selectable sample rates. We recorded electri ac ito with a frequency of one sample per secona.We the acquisition voltage range to $156 \mathrm{mV}$ wit offset curacy of $9 \mu \mathrm{V}$ to maintain a gain error of 0.1 For mechanical stimulation with $30 \mathrm{~g}$ nyl $\mathrm{n}$ cylinder, contact area with the fungal skin was c. $r_{\text {An }}$ d) c. For optical stimulation we used an aq um ht, array of LEDs, 36 white LEDs and 12 "ue EDs, $28 \mathrm{~W}$, illumination on the fungal skin was 0.

\section{Results}

Endogenous electrical activity of the fungal material is polymorphic. Low and high frequency oscillations patterns can emerge intermittently. A train of four spikes in Fig. 1c is an example of low frequency oscillations. Trains of high-frequency spikes are exemplified in Fig. 1d.

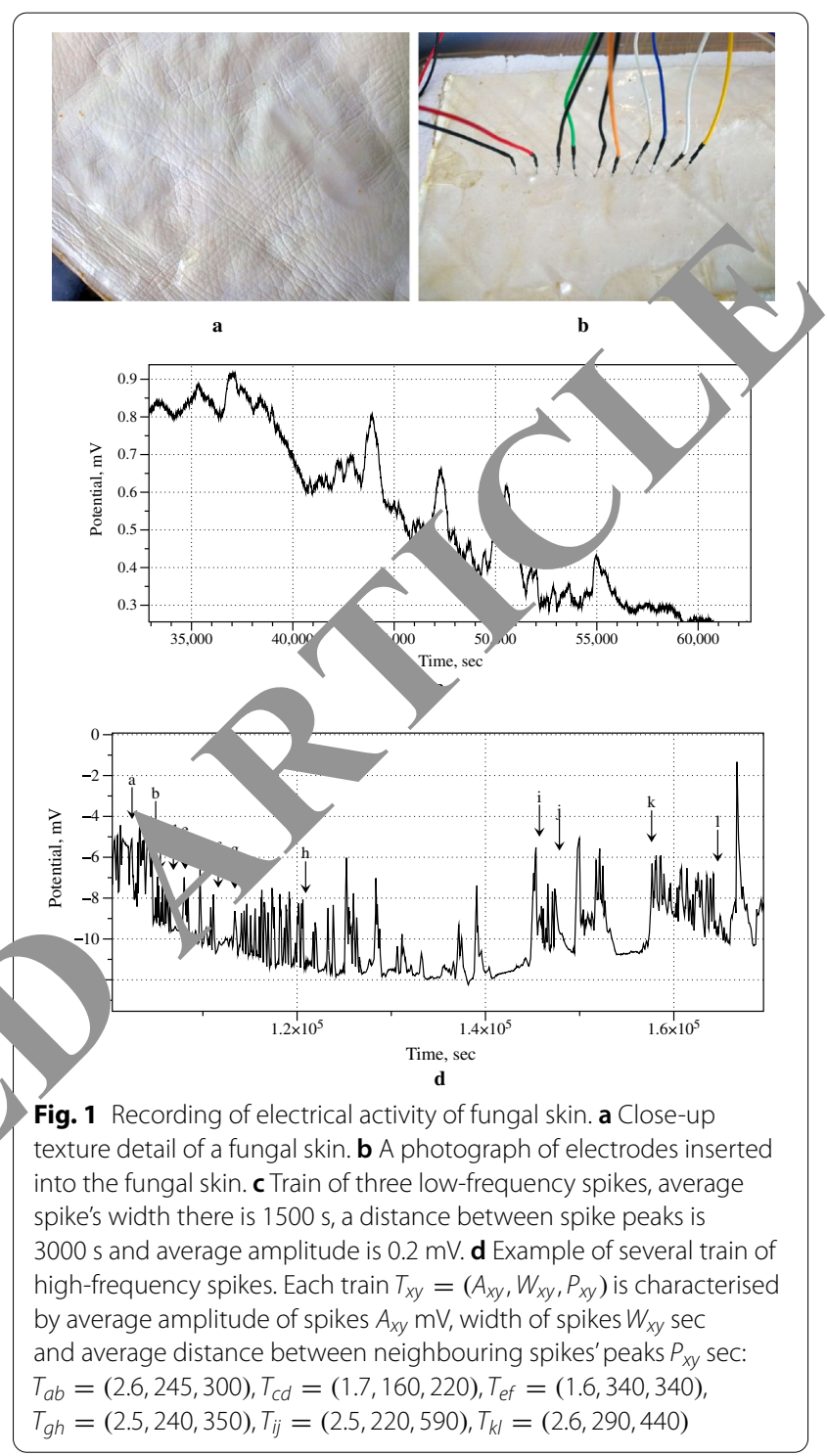

Electrical responses to tactile loading and illumination are distinctive. An example of several rounds of stimulation is shown in Fig. 2a. The fungal skin responds to loading of a weight with a high-amplitude wide spike of electrical potential sometimes followed by a train of high-frequency spikes. The skin also responds to removal of the weight by a high-amplitude spike of electrical potential.

An exemplar response to loading and removal of weight is shown in Fig. 2b. The parameters of the fungal skin responses to the weight being placed on the skin are the following. An average delay of the response (the time from weight application to a peak of the high-amplitude spike) is 911.4 $\mathrm{s}$ ( $\sigma=1280.1$, minimum $25 \mathrm{~s}$ and maximum 3200 s). An average amplitude of the response 


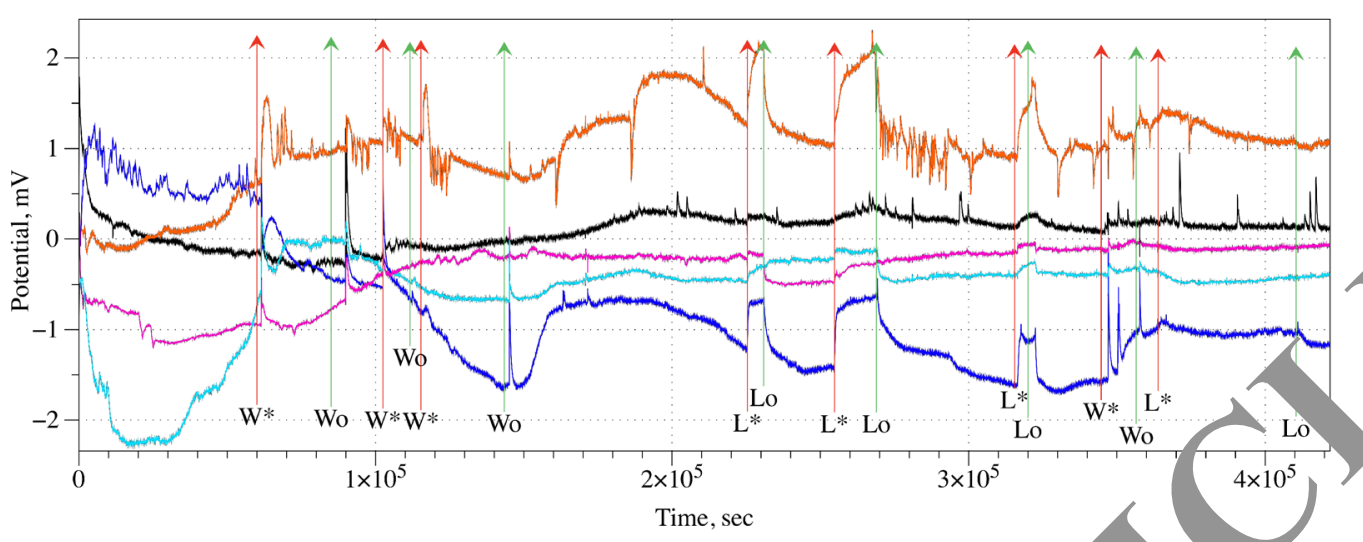

$\mathbf{a}$

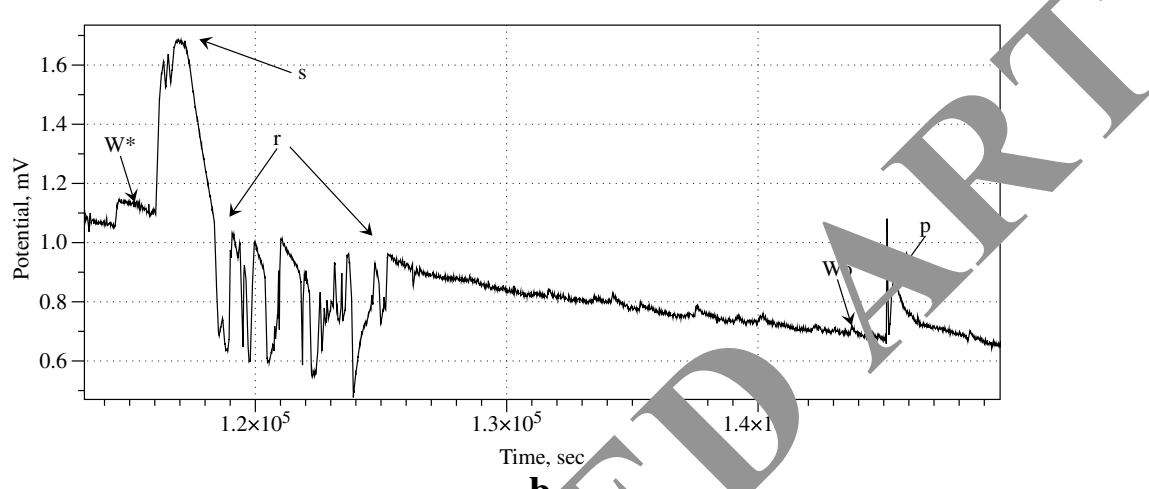

b

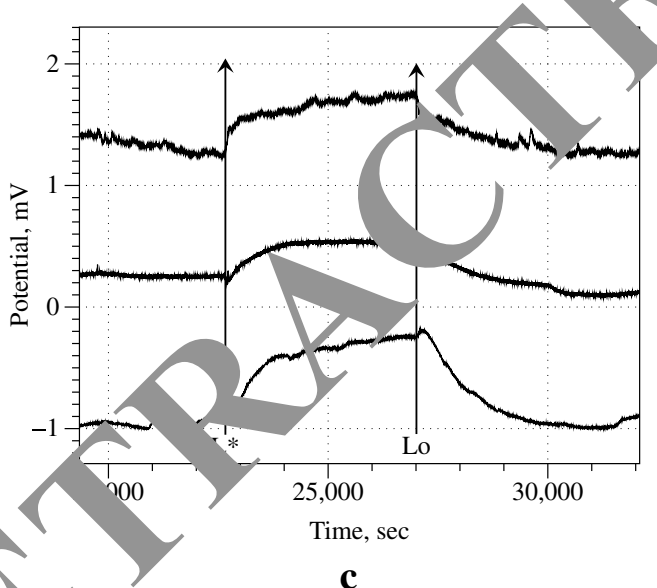

c

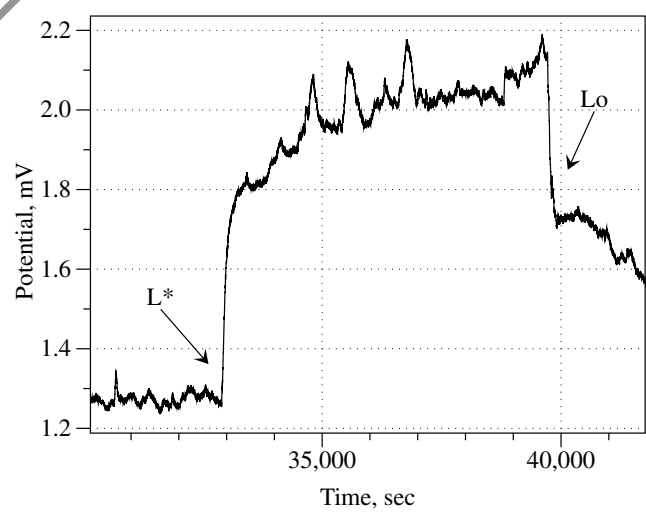

d

Fig. 2 Fu. Skin r sponse to mechanical and optical stimulation. a Exemplar recording of fungal skin electrical activity under tactile and optical ction. nents of applying and removing a weight are shown as ' $W^{* \prime}$ and 'Wo' and switching light ON and OFF as 'L*' and 'Lo'. $\mathbf{b}$ Exemplar respc se to mechanical stimulation. Moments of applying and removing a weight are shown as ' $W^{* \prime}$ and 'Wo'. High-amplitude response is labelled "IIs r o. onse is following by a train of spikes ' $r$ '. A response to the removal of the weight is labelled ' $p$ '. $\mathbf{c}$ Exemplar response of fungal skin to illu. ation, recorded on three pairs of differential electrodes. ' $L$ *'indicates illumination is applied, 'Lo'illumination is switched off. $\mathbf{d} A$ train of spikes on the raised potential as a response to illumination

spike (marked 's' in the example Fig. 2b) is $0.4 \mathrm{mV}(\sigma=$ 0.2 , minimum $0.1 \mathrm{mV}$ and maximum $0.8 \mathrm{mV})$. An average width of the response spike is $1261.8 \mathrm{~s}(\sigma=1420.3$, minimum $199 \mathrm{~s}$ and maximum $4080 \mathrm{~s})$, meaning that the average energy consumed per current unit, associated to the response, is approximately $0.5 \mathrm{~J} / \mathrm{A}$. A train of spikes (marked ' $r$ ' in the example Fig. 2b), if any, following the response spike usually has 4 or 5 spikes. The fungal 
skin responds to removal of the weight (the response is marked ' $p$ ' in the example Fig. 2b) with a spike which average amplitude is $0.4 \mathrm{mV}(\sigma=0.2$, minimum $0.2 \mathrm{mV}$ and maximum $0.85 \mathrm{mV}$ ). Amplitudes are less indicative than frequencies because an amplitude depends on the position of electrodes with regards to propagating wave of excitation. An average width of the spike is $774 \mathrm{~s}$ $(\sigma=733.1$, minimum $100 \mathrm{~s}$ and maximum $2000 \mathrm{~s}$. A response of the fungal skin to removal of the weight was not observed in c. $20 \%$ of differential electrode pairs. The average response time is $385.5 \mathrm{~s}(\sigma=693.3 \mathrm{~s}$, minimum $77 \mathrm{~s}$ and maximum $1800 \mathrm{~s}$ ).

Fungal skin's response to illumination is manifested in the raising of the baseline potential, as illustrated in the exemplar recordings in Fig. 2c. In contrast to mechanical stimulation response the response-to-illumination spike does not subside but the electrical potential stays raised till illumination is switched off. An average amplitude of the response is $0.61 \mathrm{mV}(\sigma=0.27$, minimum $0.2 \mathrm{mV}$ and maximum $1 \mathrm{mV}$ ). The raise of the potential starts immediately after the illumination is switched on. The potential reaches its maximum and goes onto plateau in $2960 \mathrm{~s}$ in average ( $\sigma=2201$, minimum $879 \mathrm{~s}$ and maximum 9530 s). Typically, we did not observe any spike trains after the illumination switched off however in a couple of trials we witnessed spike trains on top of the rosed potential, as shown in Fig. 2d.

\section{Conclusion}

We demonstrated that a thin sheet of romo neous living mycelium of Ganoderma $r$ sinaceum, which we named 'fungal skin', shows pr ounced electrical responses to mechanical and optica timulation. Can we differentiate between the noal skms response to mechanical and optical stimulation? Definitely, see Fig. 3a. The fungal skin responds to mechanical stimulation with a 15 min spike of electrical potential, which diminishes even if the applied pressure on the skin remains. The skin responds to optical stimulation by raising its electrical potential and keeping it raised till the light is switched off.

Can we differentiate the responses to loa and removal of the weight? Yes. Whilst amplitudes of ing' and 'removal' spikes are the same (C. १V in a rerage) the fungal skin average reaction tim to $\mathrm{r}$ ov of the weight is 2.4 times shorter than ke reaction to loading of the weight (385 s versus 911 s Also 'loading' spikes are 1.6 times wider than ' $r e$. 774 s).

Fungal skin responce weight pplication is, in some cases, esp. Fig. $2 y$, similar - response of slime mould to application of the $\mathrm{r}_{\text {, t }}$ theight [30]. The following events are observed 2 cillatory activity before stimulation, immediat esponse to stimulation, prolonged response timulation as a train of high-amplitude spikes, ret re $u$ normal oscillatory activity. This might indicate sor une universal principles of sensing and informia $n$ processing in fungi and slime moulds.

The ensing fungal skin proposed has a range of advanes comparing to other living sensing materials, e.g. slìne mould sensors [29-31] electronic sensors with iiving cell components [41], chemical sensors using living taste, olfactory, and neural cells and tissues [42] and tactile sensor from living cell culture [43]. The advantages are low production costs, simple maintenance, durability. The last but not least advantage is scalability: a fungal skin patch can be few microns and it can be grown to several metres in size.

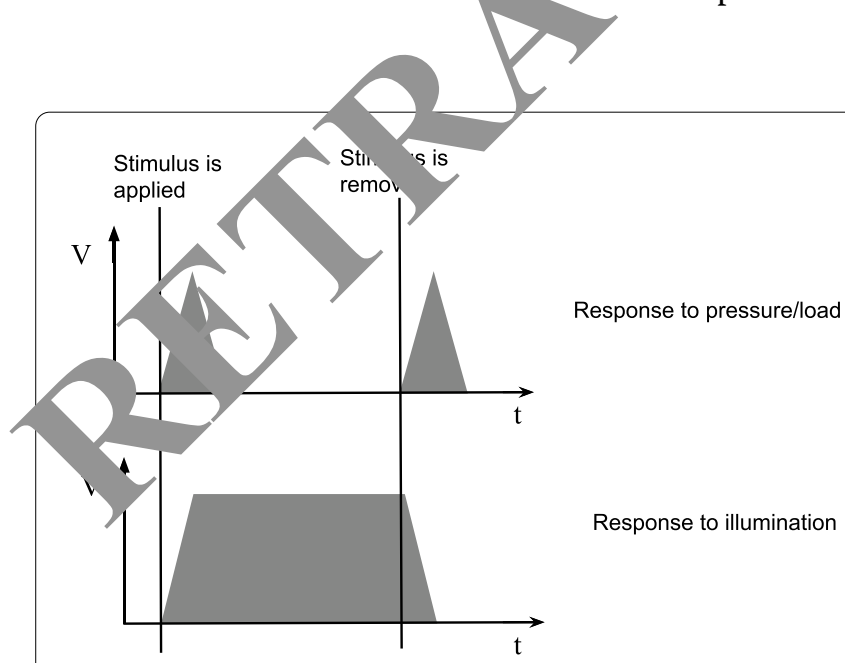

a

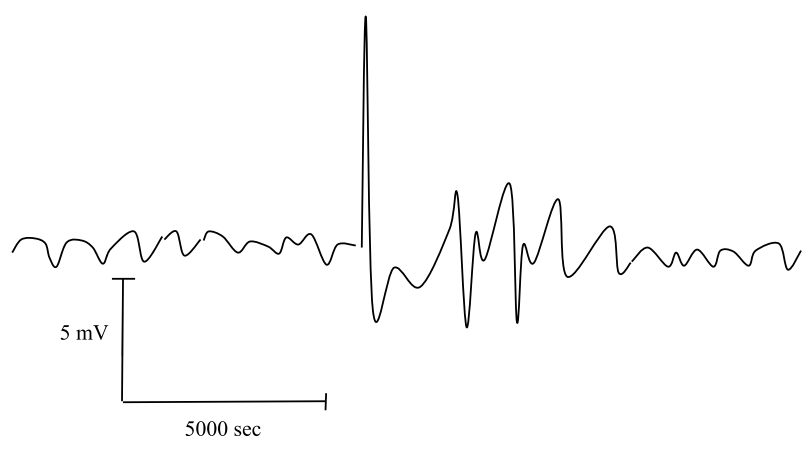

b

Fig. 3 a A scheme of the fungal skin responses to mechanical load and optical stimulations. b Slime mould P. polycephalum response to application of $0.01 \mathrm{~g}$ glass capillary tube. Redrawn from [30] 
In future studies we will aim to answer the following questions. Would it be possible to infer a weight of the load applied to the fungal skin from patterns of its electrical activity? Would the fungal skin indicate directionality of the load movement by its spiking activity? Would it be possible to locate the position of the weight within the fungal network? Would it be possible to map a spectrum of the light applied to the skin onto patterns of the skin's electrical activity?

\section{Acknowledgements}

The authors have nothing else to acknowledge.

\section{Authors' contributions}

$A A, A G, A C$ designed the experiments, analysed results and wrote the paper.

\section{Funding}

This project has received funding from the European Union's Horizon 2020 research and innovation programme FET OPEN "Challenging current thinking" under grant agreement No 858132

\section{Availability of data and materials}

The data and materials are available on request.

\section{Declarations}

\section{Ethics approval and consent to participate} Not applicable.

\section{Consent for publication}

All authors give their consent for publication.

\section{Competing interests}

Authors declare no competing interests.

\section{Author details}

${ }^{1}$ Unconventional Computing Laboratory, UWE, Bristol U...2 Mogu S. Yárzo, Italy. ${ }^{3}$ Center for Sustainable Future Technologies, Is ituto Italiano di Tecrnologia, Torino, Italy.

Received: 25 November 2020 Accepted-10 March

Published online: 17 March 2021

References

1. Soni M, Dahiyz R. eskin: dis r. outed touch sensing with harmonized energy and cu mpu. Philos Trans R Soc A. 2020;378(2164):20190156.

2. Ma M, Z Jarry Z, Liao Q, Ytan L, Zhang G, Liu S, Liao X, Zhang Y. Selfpowe d altificial electronic skin for high-resolution pressure sensing. Nano. $y .201>32: 389-96$

3. Th э० S, $\triangle$ Ele Ctronic skin with multifunction sensors based on therm. ensatio, idv Mater. 2017;29(15):1606151.

Cb 2 Jguyen A, Chortos A, To JW, Lu C, Mei J, Kurosawa T, Bae W-G, $\checkmark \mathrm{kJB}-r, \mathrm{~B} a \mathrm{O} Z$ Z. A chameleon-inspired stretchable electronic skin with ctive colour changing controlled by tactile sensing. Nat Commun. 20,5:6(1):1-10.

5. Yang T, Wang W, Zhang H, Li X, Shi J, He Y, Zheng Q-S, Li Z, Zhu H. Tactile sensing system based on arrays of graphene woven microfabrics: electromechanical behavior and electronic skin application. ACS Nano. 2015;9(11):10867-75.

6. Wang X, Dong L, Zhang H, Yu R, Pan C, Wang ZL. Recent progress in electronic skin. Adv Sci. 2015;2(10):1500169.

7. Pu X, Liu M, Chen X, Sun J, Du C, Zhang Y, Zhai J, Hu W, Wang ZL. Ultrastretchable, transparent triboelectric nanogenerator as electronic skin for biomechanical energy harvesting and tactile sensing. Sci Adv. 2017;3(5):e1700015

8. Chortos A, Liu J, Bao Z. Pursuing prosthetic electronic skin. Nat Mater. 2016;15(9):937-50.

9. Park S, Kim H, Vosqueritchian M, Cheon S, Kim H, Koo JH, Kim TR, Lee S, Schwartz G, Chang H, et al. Stretchable energy-harvesting tactile electronic skin capable of differentiating multiple mechanical stimuli modes. Adv Mater. 2014;26(43):7324-32.

10. Núñez C G, Manjakkal L, Dahiya R. Energy autonomous electro nic skin. NPJ Flexible Electron. 2019;3(1):1-24.

11. Wang C, Hwang D, Yu Z, Takei K, Park J, Chen T, Ma B, Javey A. Us "vteractive electronic skin for instantaneous pressure visualization. Nat 2013;12(10):899-904.

12. Wang X, Gu Y, Xiong Z, Cui Z, Zhang T. Silk-mold" ed fle ultra ensitive, and highly stable electronic skin for monite ring human ological signals. Adv Mater. 2014;26(9):1336-42.

13. Sekitani T, Someya T. Stretchable organic grated ci cuits for large-area electronic skin surfaces. Mrs Bull.?

14. Guo H, Lan C, Zhou Z, Sun P, Wri D, L. Transparent, flexible, and stretchable ws 2 based hum dity sensol electronic skin. Nanoscale. 2017;9(19):6246-53

15. Qiao $Y$, Wang $Y$, Tian H, LM M, Jià Wei Y, Tian Y, Wang D-Y, Pang Y, Geng X, et al. Multilayer one epidt al electronic skin. ACS Nano.
2018;12(9):8839 46 .

16. Zhao X, Hua \&, Z añ C. Flexible, stretchable and wearable multifunctional se. array as artificial electronic skin for static and dynam- strain mapp. Adv Electron Mater. 2015;1 (7):1500142.

17. Scalisi R, Mavetto A, Stoppa M, Ariano P, Pandolfi P, Chiolerio A. Inkjet prin ted itit, ve electrodes for surface electromyography. Organ Electron. 2 15;18:89-94.

Chiolerio A, Aívolo P, Porro S, Stassi S, Ricciardi S, Mandracci P, Canavese G, tka K, Pirri CF. Inkjet-printed pedot: pss electrodes on plasma modified s nanocomposites: quantifying plasma treatment hardness. RSC Adv. 4;4:51477.

hiolerio A, Adamatzky A. Tactile sensing and computing on a random network of conducting fluid channels. Flexible Print Electron. 2020;5:025006.

20. Adamatzky A, Ayres P, Belotti G, Wösten H. Fungal architecture position paper. Int J Unconvent Comput. 2019;14:397-441.

21. El-Hussieny H, Mehmood U, Mehdi Z, Jeong S-G, Usman M, Hawkes EW, Okarnura AM, Ryu J-H. Development and evaluation of an intuitive flexible interface for teleoperating soft growing robots, In: 2018 IEEE/RSJ International Conference on Intelligent Robots and Systems (IROS), IEEE, 2018;4995-5002.

22. Sadeghi A, Mondini A, Mazzolai B. Toward self-growing soft robots inspired by plant roots and based on additive manufacturing technologies. Soft Robot. 2017;4(3):211-23.

23. Rieffel J, Knox D, Smith S, Trimmer B. Growing and evolving soft robots. Artif Life. 2014;20(1):143-62.

24. Greer JD, Morimoto TK, Okamura AM, Hawkes EW. A soft, steerable continuum robot that grows via tip extension. Soft Robot. 2019;6(1):95-108.

25. Meyer V, Basenko EY, Benz JP, Braus GH, Caddick MX, Csukai M, de Vries RP, Endy D, Frisvad JC, Gunde-Cimerman N, Haarmann T, Hadar Y, Hansen K, Johnson RI, Keller NP, Kraševec N, Mortensen UH, Perez R, Ram AFJ, Record E, Ross P, Shapaval V, Steiniger C, van den Brink H, van Munster J, Yarden O, Wösten HAB. Growing a circular economy with fungal biotechnology: a white paper. Fungal Biol Biotechnol. 2020;7(1):5. https://doi.org/ 10.1186/s40694-020-00095-z.

26. Haneef M, Ceseracciu L, Canale C, Bayer IS, Heredia-Guerrero JA, Athanassiou A. Advanced materials from fungal mycelium: fabrication and tuning of physical properties. Sci Rep. 2017;7(1):1-11.

27. Jones M, Mautner A, Luenco S, Bismarck A, John S. Engineered mycelium composite construction materials from fungal biorefineries: a critical review. Mater Design. 2020;. https://doi.org/10.1016/j.matdes.2019. 108397.

28. Wösten HAB. Filamentous fungi for the production of enzymes, chemicals and materials. Curr Opin Biotechnol 2019;59:65-70. https://doi.org/ 10.1016/J.COPBIO.2019.02.010https://www.sciencedirect.com/science/ article/abs/pii/S0958166918302283.

29. Adamatzky A. Towards slime mould colour sensor: recognition of colours by physarum polycephalum. Organ Electron. 2013;14(12):3355-61. 
30. Adamatzky A. Slime mould tactile sensor. Sensors Actuat B Chem. 2013;188:38-44.

31. Whiting J G, de Lacy Costello B P, Adamatzky A. Towards slime mould chemical sensor: mapping chemical inputs onto electrical potential dynamics of physarum polycephalum. Sensors Actuat B Chem. 2014;191:844-53.

32. Adamatzky A. On spiking behaviour of oyster fungi pleurotus djamor. Sci Rep. 2018;8(1):1-7.

33. Beasley AE, Powell AL, Adamatzky A. Capacitive storage in mycelium substrate, arXiv preprint arXiv:2003.07816.

34. Beasley A, Abdelouahab M-S, Lozi R, Powell A, Adamatzky A. Mem-fractive properties of mushrooms, arXiv preprint arXiv:2002.06413v2.

35. Hamlyn PF. Fabricating fungi. In: Glasman I, Lennox-Kerr P, editors. New applications. Textile Technology International, Sterling Publications Ltd: London; 1991. p. 254-7.

36. Hamlyn PF, Schmidt RJ. Potential therapeutic application of fungal filaments in wound management. Mycologist. 1994;8(4):147-52. https://doi. org/10.1016/S0269-915X(09)80176-6.

37. Su C-H, Sun C-S, Juan S-W, Hu C-H, Ke W-T, Sheu M-T. Fungal mycelia as the source of chitin and polysaccharides and their applications as skin substitutes. Biomaterials. 1997;18(17):1169-74.
38. Su C-H, Sun C-S, Juan S-W, Ho H-O, Hu C-H, Sheu M-T. Development of fungal mycelia as skin substitutes: effects on wound healing and fibroblast. Biomaterials. 1999;20(1):61-8.

39. Xu H, Liu L, Cao C, Lu W, Zhu Z, Guo Z, Li M, Wang X, Huang D, Wang S, et al. Wound healing activity of a skin substitute from residues of culinarymedicinal winter mushroom flammulina velutipes (agaricomycetes) cultivation. Int J Med Mushrooms. 2019;21(7):683-91.

40. Narayanan KB, Zo SM, Han SS. Novel biomimetic chitin-glucan ps 'saccharide nano/microfibrous fungal-scaffolds for tissue engine ingapplications. Int J Biol Macromol. 2020;149:724-31. https://doi.0ry 10 s/j. ijbiomac.2020.01.276.

41. Kovacs GT. Electronic sensors with living cellular components. Pro 2003;91(6):915-29.

42. Wu C, Lillehoj PB, Wang P. Bioanalytical and che 'nical ors usi ig living taste, olfactory, and neural cells and tis aes: a short in Analyst. 2015;140(21):7048-61.

43. Minzan K, Shimizu M, Miyasaka K, Ogrura 7 kai J, Ohk Ura M, Hosoda K. Toward living tactile sensors. In: Co renc hiom, metic and biohybrid systems, Springer, 2013, p 109-

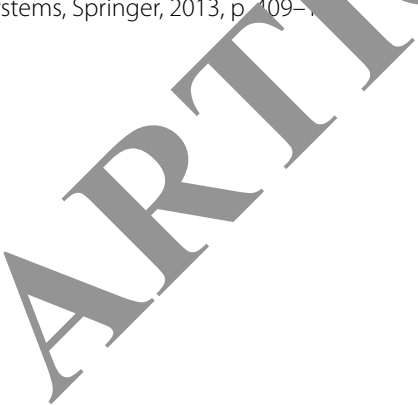

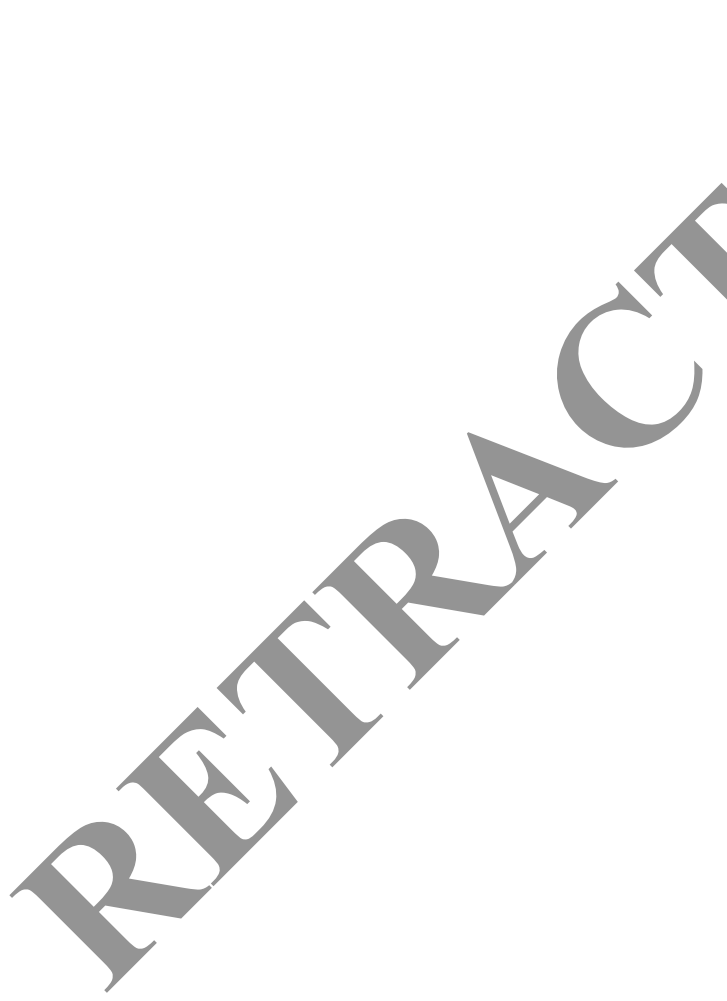

Ready to submit your research? Choose BMC and benefit from:

- fast, convenient online submission

- thorough peer review by experienced researchers in your field

- rapid publication on acceptance

- support for research data, including large and complex data types

- gold Open Access which fosters wider collaboration and increased citations

- maximum visibility for your research: over $100 \mathrm{M}$ website views per year

At BMC, research is always in progress.

Learn more biomedcentral.com/submissions 